\title{
Effect and cognition of hole filling measures in ultra-low permeability reservoir block
}

\author{
Ziwei $\mathrm{Li}^{*}$ \\ Third Oil Mine, Daqing Oilfield Company Limited, Tenth Oil Production Plant, Daqing, Heilongjiang 166405, China
}

\begin{abstract}
In this paper, based on the application of water-flooded layer interpretation plate, multi-well comparison, and the combination of dynamic and static analysis methods to optimize the well selection of fill hole wells, and through the analysis of the production of fill hole wells in **block in recent years, we summarize the relationship between fill hole effect and fill hole well injection and extraction well spacing, connection relationship, water content before the measure, and the relationship between fill opening thickness of the patch opening, so as to provide reference for the next step to continue to carry out fill hole work and find fill hole potential.
\end{abstract}

Keywords: Encrypted wells, hole filling, effect

\section{Problem formulation}

Over the past few years, a total of 275 encrypted oil recovery wells have been put into production in Block A. Since the old block had been developed with water injection for more than 10 years at the time of encryption, the distribution of subsurface oil and water was complicated and the water flooding condition in some well areas was serious, the layers with the same oil and water layer, a higher degree of water flooding and a higher risk of hole injection explained at the time of encryption well injection were not injected. Of the 275 oil production wells that were encrypted, a total of 90 wells were not completely shot open, with 179 total un-shot layers and a total un-shot thickness of $435.3 \mathrm{~m}$. After densification, through the adjustment of the injection and extraction system and the adjustment of the water injection scheme, the subsurface oil and water are redistributed and some of the un-injected layers have a certain potential for hole filling.

\section{Application of oil recovery well filling technology to improve the relationship of the injection and extraction and increase the degree of reserve utilization}

\subsection{Small injection and extraction well spacing, After hole filling to increase the liquid and oil effect becomes better, But there is a risk of rising water content.}

Among the 28 wells in the fill hole, 10 wells with $140 \mathrm{~m}$ injection and extraction distance, 10 wells with $210 \mathrm{~m}$ injection and extraction distance and 8 wells with $237 \mathrm{~m}$ injection and extraction distance. The wells with $210 \mathrm{~m}$ spacing between injection and extraction wells have the best effect after hole patching; the wells with $140 \mathrm{~m}$ distance between injection and extraction has a large fluid increase after hole patching, but the water content is high, and after water injection adjustment, it has an oil increase effect; the wells with $237 \mathrm{~m}$ injection and extraction spacing are less effective due to the larger well spacing. The 140m well spacing fill hole well has good fluid and oil increase effect, but the water content is high, through the water injection adjustment, a certain oil increase effect can be achieved. There are 10 wells with $140 \mathrm{~m}$ spacing between injection and extraction wells, producing $2.2 \mathrm{t}$ of liquid per day, $0.6 \mathrm{t}$ of oil per day and $72.7 \%$ of water before filling the hole, $9.0 \mathrm{t}$ of liquid per day, $1.9 \mathrm{t}$ of oil per day and $78.6 \%$ of water have been produced in the initial stage after filling the hole, and well increasing $1.3 \mathrm{t}$ of oil per day and 5.9 percentage points of water, currently producing $5.9 \mathrm{t}$ of liquid per day, $0.8 \mathrm{t}$ of oil per day and

\footnotetext{
* Corresponding author: liziwei@petrochina.com.cn
} 
$86.5 \%$ of water with a current average single well increasing, the current average daily oil increase per well is $0.2 \mathrm{t}$. Due to the small well spacing of $140 \mathrm{~m}$, the increase in fluid after the fill hole is larger, and the rise in water content is also larger, but through the comprehensive adjustment of water injection after the fill hole, a certain effect of oil increase can be achieved. The effect of $210 \mathrm{~m}$ well spacing of hole patching wells to increase fluid and oil is good. There are 10 wells with $210 \mathrm{~m}$ well spacing, 8 wells with good effect after filling, with $80 \%$ efficiency, and 2 wells with poor effect, which are mainly affected by oil layer interference.

Before the measure, it produced $1.8 \mathrm{t}$ of liquid per day, $1.1 \mathrm{t}$ of oil per day containing $39.9 \%$ of water. In the initial stage after filling the hole, it produced $6.5 \mathrm{t}$ of liquid per day, $4.5 \mathrm{t}$ of oil per day, and increased $3.4 \mathrm{t}$ of oil per day containing $30 \%$ water, now it produces 3.1 t of liquid per day, $1.6 \mathrm{t}$ of oil per day containing $49.5 \%$ water, with an average single well validity of $522 \mathrm{~d}$ and a cumulative increase of $637 \mathrm{t}$ of oil. There are 8 wells with $237 \mathrm{~m}$ of injection and extraction well spacing, of which 5 are effective, with $62.5 \%$ measure efficiency. Due to the large distance between wells, the effect of fluid and oil increase is the worst. The average daily oil increase of a single well is 2.0t. In the initial stage after filling the hole, and the average daily oil increase of a single well is $0.2 \mathrm{t}$ at present, with an average single well validity of $325 \mathrm{~d}$ and an accumulated oil increase of $298 \mathrm{t}$.

\subsection{The effect is good after filling wells with moderate fluid production and low to medium water content before the measure}

According to the relationship between daily liquid production, water content before the measure and the initial daily oil increase after the measure, it can be seen that: both curves are parabolic, when the daily liquid production is less than $1.0 \mathrm{t}$ or more than $2.5 \mathrm{t}$, the effect of the measure becomes worse, the liquid volume before the measure is low, which means that the liquid supply capacity of the area is insufficient, and the oil increase after the fill hole is relatively poor, when the liquid volume is high and the water content is higher than $40.0 \%$, the liquid output capacity of the shot hole layer is strong, the degree of water flooding is high, and the new fill open layer. The effect of measures is relatively poor because of inter-layer interference.

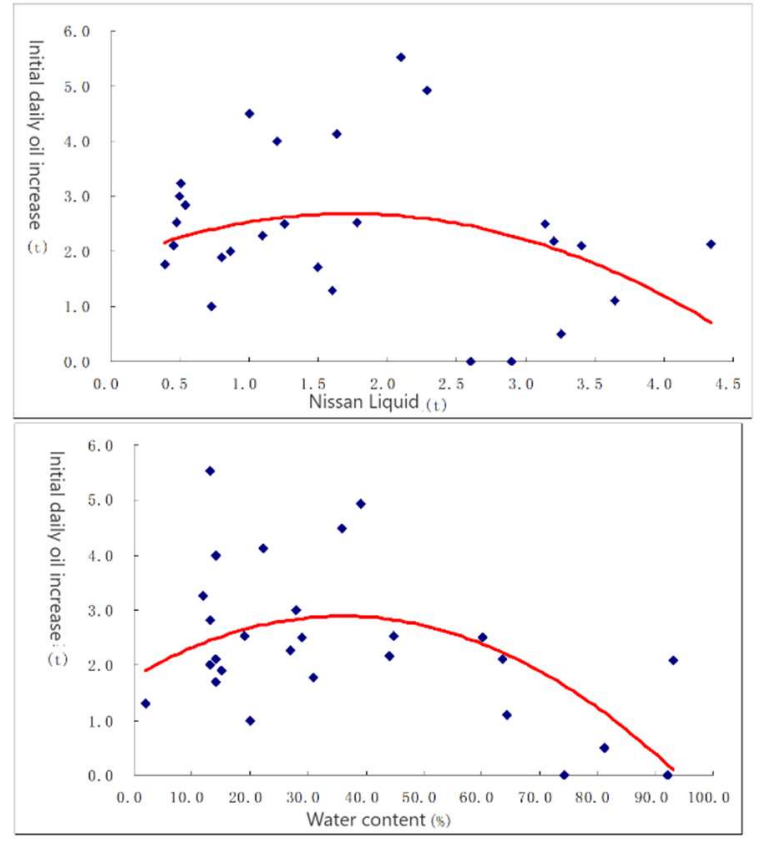

Figure 1 Relationship between daily fluid production and water content before the measure and daily oil gain in the initial period after the measure 
Statistical analysis was performed on 28 fill hole wells, which were divided into 3 intervals: fluid production before the measure was less than $1.0 \mathrm{t}$ and water content was less than $40.0 \%$; fluid production was between 1.0 $2.5 \mathrm{t}$ and water content was less than $40.0 \%$; fluid production was more than $2.5 \mathrm{t}$ and water content was more than $40.0 \%$.From the statistical results, it shows that there are 10 wells producing 1.0-2.5t with water content less than $40.0 \%, 8$ effective wells, $80.0 \%$ measure efficiency, $3.3 \mathrm{t}$ daily oil increase in the initial stage, $0.3 \mathrm{t}$ daily oil increase at present, 487 days validity, 579t cumulative oil increase; 9 wells producing less than $1.0 \mathrm{t}$ with water content less than $40.0 \%, 7$ effective wells, $77.8 \%$ measure efficiency, $2.2 \mathrm{t}$ daily oil increase at the beginning, $0.5 \mathrm{t}$ daily oil increase at present, 405 days validity, $404 \mathrm{t}$ cumulative oil increase, 5 wells are still effective at present. The initial daily oil increase of $2.2 \mathrm{t}$, the current daily oil increase of $0.5 \mathrm{t}$, valid for 405 days, cumulative oil increase of 404t, 5 wells are still effective, the type of wells after the fill open water content rose greatly, indicating that although has shot open layer poor fluid supply, low fluid production before the measure, but the fill hole layer may be medium water flooding, a larger increase in fluid, with the effect of oil increase; fluid production greater than $2.5 \mathrm{t}$, water content greater than $40.0 \%$ of the 9 wells The effect is good 3 wells, the measure efficiency $33.3 \%$, affected by inter-layer interference, the effect is poor, the initial daily oil increase of 2.2t, currently ineffective, valid for 204 days, cumulative oil increase of 191t.

\subsection{Water-driven wells with large reservoirs and good connectivity are effective in filling holes}

The larger the water-driven reserves of the fill hole well, the better the results. The 28 wells that were filled with holes increased water-driven reserves by a total of $15.03 \times 104 t$, with an average of $0.54 \times 104 t$ of water-driven reserves added to a single well

The relationship between water-driven active reserves and initial daily oil gain and cumulative oil gain shows that: the larger the water-driven active reserves, the higher the initial daily oil production and cumulative oil gain of the make-up well. The effect is better if the well is well connected.

The average single well injection pressure is $11.2 \mathrm{MPa}$, daily water injection is $18 \mathrm{~m} 3$, cumulative water injection is $5.42 \times 104 \mathrm{~m} 3$. 20 wells have good connection relationship, 13 wells have good effect after taking measures, the efficiency of measures is $65.0 \%$, the average single well connection is 2.3 water injection wells, the average injection and extraction well distance is $210 \mathrm{~m}$, the main oil layer is two-way and The average single-well daily oil increase was $2.2 \mathrm{t}$ at the beginning after the hole patching, and now the average single-well daily oil increase is $0.5 \mathrm{t}$, the average single-well validity is $401 \mathrm{~d}$, and the cumulative oil increase is $454 \mathrm{t}$; 8 wells have poor connection relationship, 5 wells have good effect after the measure, the measure efficiency is $62.5 \%$, the average single-well connection is 1.4 water injection wells, the average injection and extraction well distance is $225 \mathrm{~m}$, the main oil layer two-way and above is $22.0 \%$. The average daily oil increase in a single well is $2.5 \mathrm{t}$ at the beginning of the period after the hole patching, and the current average daily oil increase in a single well is $0 t$, with an average single well validity of $257 \mathrm{~d}$ and an accumulated oil increase of $216 \mathrm{t}$.

\subsection{Good results in making up for oil formation thickness and making up for oil recovery wells with large main oil formation thickness}

According to the thickness of the fill-opened oil layer, the thickness of the fill-opened main oil layer, the initial daily oil increase and cumulative oil gain relationship, it can be seen that: the thickness of the fill-opened oil layer and the thickness of the fill-opened main oil layer are large, the activated reserves are large, and the fill-opening effect is better.

From the statistical table of the effect of measures, we can see that there are 18 wells with thickness greater than $5.0 \mathrm{~m}$, including 12 wells with good effect, $66.7 \%$ of the effective measures, $2.3 \mathrm{t}$ of oil increase per day at the beginning after filling the hole, $420 \mathrm{~d}$ of the average single well validity, $468 \mathrm{t}$ of cumulative oil increase; 10 wells with thickness less than $5.0 \mathrm{~m}$, including 6 wells with good effect, $60.0 \%$ of the effective measures The initial daily oil increase was $2.2 \mathrm{t}$, the average single well validity was $279 \mathrm{~d}$, and the cumulative oil increase was $273 \mathrm{t}$.

\section{Conclusion and Awareness}

3.1 In encryption, the small layer that is not shot open can be selectively filled with holes, which can achieve a certain effect of oil increase.

3.2 The effect of filling wells with $210 \mathrm{~m}$ and $140 \mathrm{~m}$ injection and extraction spacing is better than that of wells with $237 \mathrm{~m}$ injection and extraction spacing, but the $140 \mathrm{~m}$ well spacing is closer and there is a risk of water content rising after filling.

3.3 Priority should be given to wells with fluid volumes $<2.5 \mathrm{t}$ and medium and low water content for hole filling. For oil recovery wells with high fluid volume and high water content, in order to avoid inter-layer interference affecting the effect of hole filling, the high water-bearing layer in the initial injection opening level should be blocked first to improve the oil enhancement effect of the measure.

3.4 The water drive is more effective in filling holes in wells with large reserves and good connectivity.

3.5 Better results for wells with a large formation thickness and a large main formation thickness

\section{References}

1. Li Daopin. Development of low permeability sandstone oil fields [M]. Beijing: Petroleum Industry Press. 1997.

2. XuQi et al. Seepage characteristics of extra-low permeability reservoirs and the law of water drive development [M]. Beijing: Petroleum Industry Press.2019. 
3. Lu Baoping. New advances in petroleum engineering technology [M]. Beijing: Sinopec Publishing House. 2014.

4. Lian Qingcun. Oil reservoir engineering [M]. Beijing: Petroleum Industry Press. 2006.

5. Li Daopin. Decision Theory of Efficient Development of Low Permeability Reservoirs [M]. Beijing: Petroleum Industry Press. 2003.

6. Chen Taoping. Petroleum Engineering [M]. Beijing: Petroleum Industry Press. 2000. 